\title{
Design of Compact Dual Notched Self-Complementary UWB Antenna
}

\author{
K. S. Sultan'1,2, O. M. A. Dardeer ${ }^{1}$, H. A. Mohamed ${ }^{1}$ \\ ${ }^{1}$ Electronics Research Institute, El-Tahreer St. Dokki, Giza, Egypt \\ ${ }^{2}$ Zewail City of Science and Technology, Giza, Egypt \\ Email: kamelsultan@eri.sci.eg
}

How to cite this paper: Sultan, K.S., Dardeer, O.M.A. and Mohamed, H.A. (2017) Design of Compact Dual Notched Self-Complementary UWB Antenna. Open Journal of Antennas and Propagation, 5, 99-109.

https://doi.org/10.4236/ojapr.2017.53008

Received: June 12, 2017

Accepted: September 8, 2017

Published: September 11, 2017

Copyright (c) 2017 by authors and Scientific Research Publishing Inc. This work is licensed under the Creative Commons Attribution International License (CC BY 4.0).

http://creativecommons.org/licenses/by/4.0/

\begin{abstract}
In this paper, a novel double notched UWB antenna is introduced. The proposed antenna is Quasi Self-Complementary (QSC) with wide impedance bandwidth from $2.2 \mathrm{GHz}$ to more than $12 \mathrm{GHz}$. The antenna consists of semi-ring with rectangular tapered section for more matching and it is designed on FR-4 substrate with thickness $1.5 \mathrm{~mm}$ and has compact size of 11.5 $\times 14.5 \times 1.5 \mathrm{~mm}^{3}$. The dual notched bands are achieved by using a T-shaped slit etched in the radiating patch to reject interference with WIMAX band and two C-shaped are placed close to the microstrip feed line to reject the interference with the WLAN band. The proposed antenna is designed, simulated and measured. All simulation results are performed using the CST software. Good agreement is presented between the experimental and the simulated results.
\end{abstract}

\section{Keywords}

Monopole, Ultra Wide Band (UWB), Self-Complementary, Notch,

Wireless Local Area Network (WLAN)

\section{Introduction}

The Ultra-Wide Band (UWB) technology has become more popular due to various applications such as medical imaging applications, multimedia connectivity, personal communications, ground penetrating radar and sensor networks. Also, the UWB system plays as one of the very important leading wireless communication systems due to low power consumption, high speed, and efficient frequency. In the current, the FCC has allocated at bandwidth of $7.5 \mathrm{GHz}$ of ultra-wideband devices in the band from 3.1 to $10.6 \mathrm{GHz}$ [1] [2]. Nowadays, the UWB antenna needs many requirements such as wide bandwidth, radiation stability, constant gain and compact size [3] [4]. Through the last years, different 
methods to integrate the Bluetooth band with UWB are introduced [5] [6] [7]. Xiong et al. [5] introduce an UWB antenna with wide bandwidth from $2.2 \mathrm{GHz}$ to $10.6 \mathrm{GHz}$ and add slot on the current path to filter out the band between Bluetooth and UWB [5]. In [6], a dual band U shaped monopole is introduced with adding strip line for Bluetooth band. The antenna is designed on FR4 substrate with thickness $1.6 \mathrm{~mm}$, and size $50 \mathrm{~mm} \times 24 \mathrm{~mm}$ where the length of the antenna is increased due to strip line.

On the other hand, extensive research efforts are exerted in minimizing the size of microstrip antenna especially UWB antenna [8] [9] [10] [11]. In 2012, a novel monopole antenna with Koch fractal boundary is introduced with compact size $20 \mathrm{~mm} \times 15 \mathrm{~mm}$ to cover bandwidth from 4.3 to $12 \mathrm{GHz}$ [9]. In 2013 [11], Quasi Self-Complementary Antenna (QSCA) with size $16 \times 25 \mathrm{~mm}^{2}$ was introduced for UWB. Moreover, In 2016 [12], Wahab et al. introduced Quasi self-complementary fractal UWB antenna with size $15 \times 13 \times 1.5 \mathrm{~mm}^{3}$. In 2017 [13], Frequency Selective Surface (FSS) was used to improve the UWB antenna performance. The main property of the Self-Complementary Antenna (SCA) is having constant impedance where the antenna is SCA when the metal area and the open area are congruent. Moreover, the currently allocated UWB frequency band will cause interference in the existing wireless communication systems, such Wireless Local Area Network (WLAN) bands (5.15 - $5.35 \mathrm{GHz}, 5.725$ $5.825 \mathrm{GHz}$ ), and the World Interoperability for Microwave Access (WiMAX) band (3.4 - 3.69 GHz), hence, the UWB antenna with single and dual band-stop performances is required [14]-[19]. The most common approach is embedding a slot into the radiating patch to change the current flow. Different shapes of the slots (such as U-shaped, Hilbert-curve, mender line, ring, square, C-shaped and T-shaped) are used to obtain the desired band notched [14]-[19].

In this paper, a QSCA is introduced to achieve wide impedance bandwidth integrated with Bluetooth. The proposed antenna has compact size of $11.5 \times 14.5$ $\mathrm{mm}^{2}$. The UWB antenna is fabricated on a FR4 substrate with relative permittivity of 4.5 , and thickness of $1.5 \mathrm{~mm}$.

The paper is organized as follows: Section 2 describes the design of antenna without notch and its results. Section 3 explains the antenna performance with notch and compares it between simulated and measured results. Finally, Section 4 presents the conclusions for this paper.

\section{Antenna Design without Notch}

\subsection{Antenna Geometry}

The QSCA fed by a 50-microstrip line is shown in Figure 1, which is designed on an FR4 substrate of thickness $1.5 \mathrm{~mm}$, permittivity 4.5 , and loss tangent 0.025 with compact size $(11.5 \times 14.5 \times 1.5) \mathrm{mm}^{3}$. The proposed antenna consists of semi ring with staircase shape and tapered fed line $50 \Omega$ of width $W_{f}$ at the feed point and linear tapered to width $W_{i}$ at the patch to match with high impedance of semi ring. All the labelled dimensions are tabulated in Table 1. The antenna is 


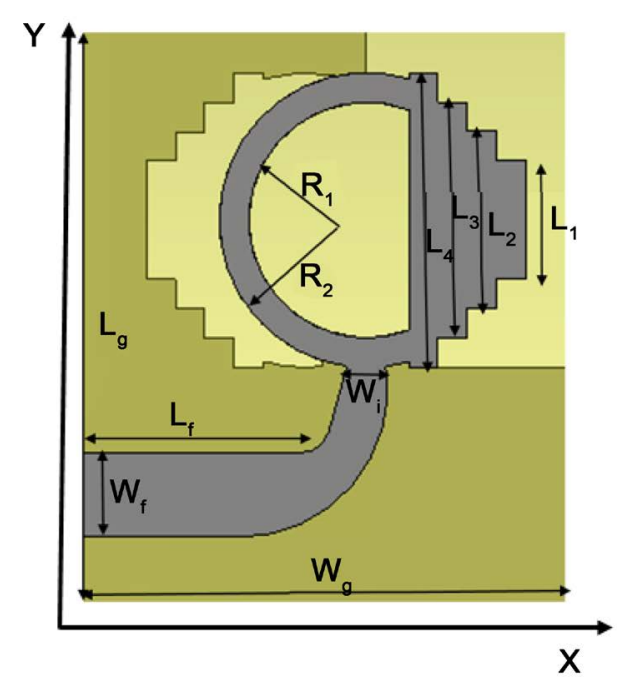

(a)

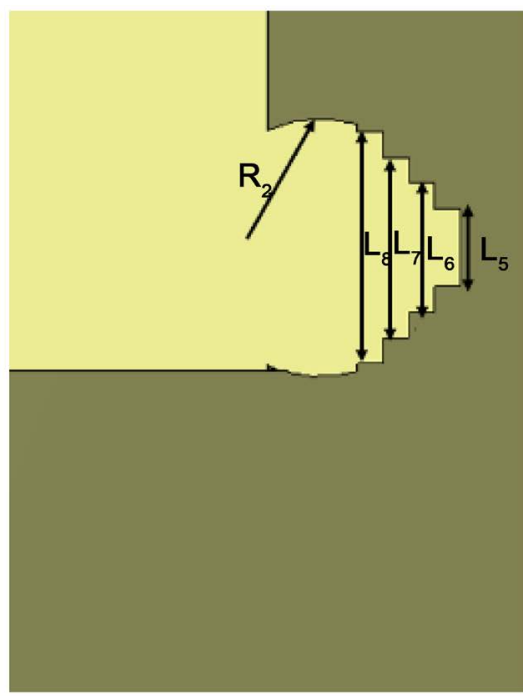

(b)

Figure 1. Geometry of the proposed antenna. (a) Front View; (b) Back view.

Table 1. Antenna Parameters (all dimensions in $\mathrm{mm}$ ).

\begin{tabular}{ccccccccc}
\hline Parameter & $R_{1}$ & $R_{2}$ & $L_{1}$ & $L_{2}$ & $L_{3}$ & $L_{4}$ & $L_{5}$ & $L_{6}$ \\
\hline Value & 4 & 5 & 4 & 6 & 8 & 11 & 4 & 6 \\
\hline Parameter & $L_{7}$ & $L_{8}$ & $L_{g}$ & $L_{f}$ & $W_{f}$ & $W_{g}$ & $W_{i}$ & \\
\hline Value & 8 & 11 & 14.5 & 5 & 2.58 & 16 & 1.4 & \\
\hline
\end{tabular}

designed through 5 steps, the following section shows the antennas design procedures and results.

\subsection{Design Procedures}

The important criteria in the design of the desired UWB antenna are adjusting the impedance bandwidth. So, the proposed antenna is designed through five steps as shown in Figure 2. The first configuration, Ant. 1 is designed as conventional planar circular disc monopole antenna with radius $15 \mathrm{~mm}$ and the partial ground plane is used to enhance the matched impedance of the UWB antenna from $2.2 \mathrm{GHz}$ to $12 \mathrm{GHz}$. To accomplish a compact size design, the second configuration is introduced to minimize the size, the semi-circular is designed with the same radius but the return loss is not matched with the overall UWB. In Ant. 3, the semi-circular with step rectangular is introduced for enhancement the bandwidth and semi-circular is opened in the ground plan to complementary with the patch. Ant. 4 and Ant. 5 are introduced for more matching, compact size and integrate the Bluetooth. Figure 3 shows the comparison between the return losses of different configurations. From the figure we note that Ant. 1 have large size and good performance at the same time and to minimize the size, the others antennas are introduced. Ant. 2 don't have good matching through overall band. So, the self-complementary is introduced to enhance the bandwidth of the antenna as shown in the figure. 


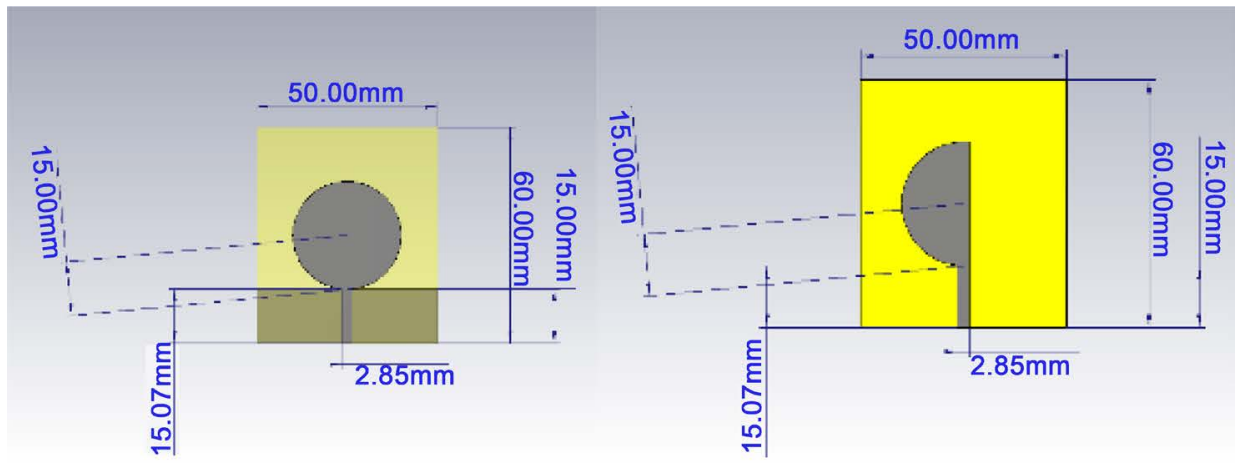

(a)

(b)

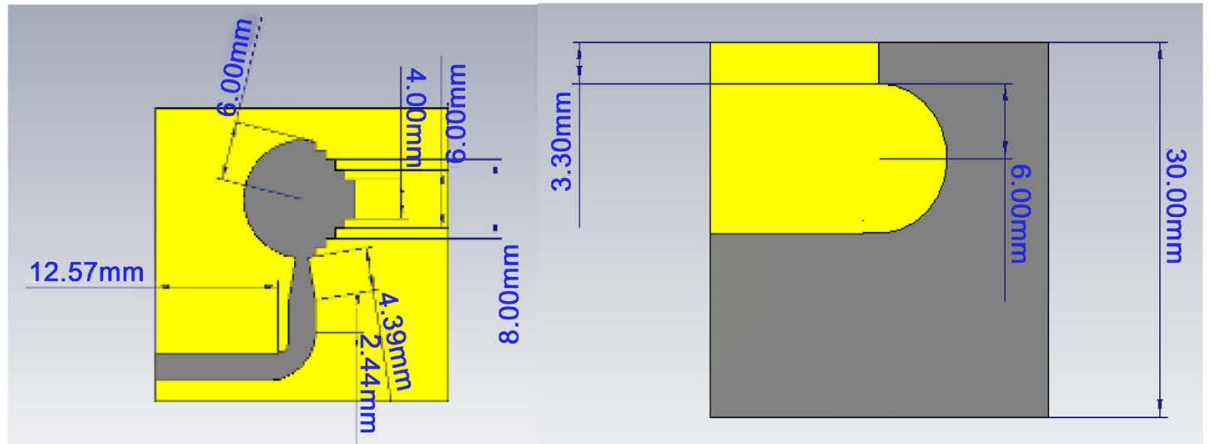

(c)

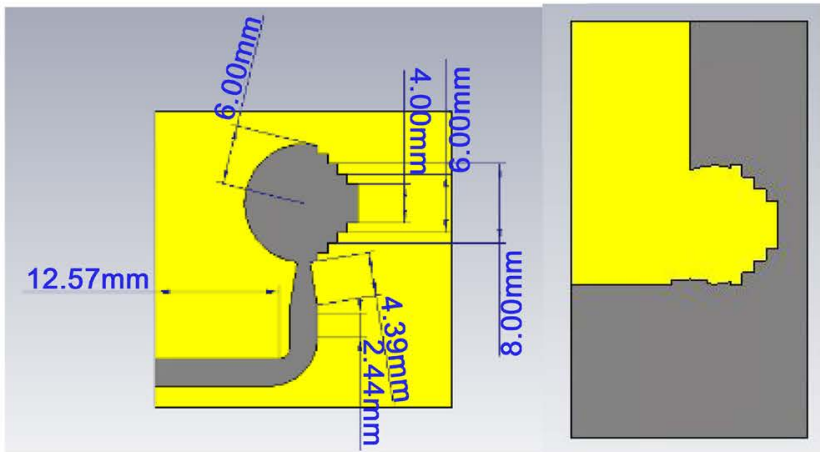

(d)
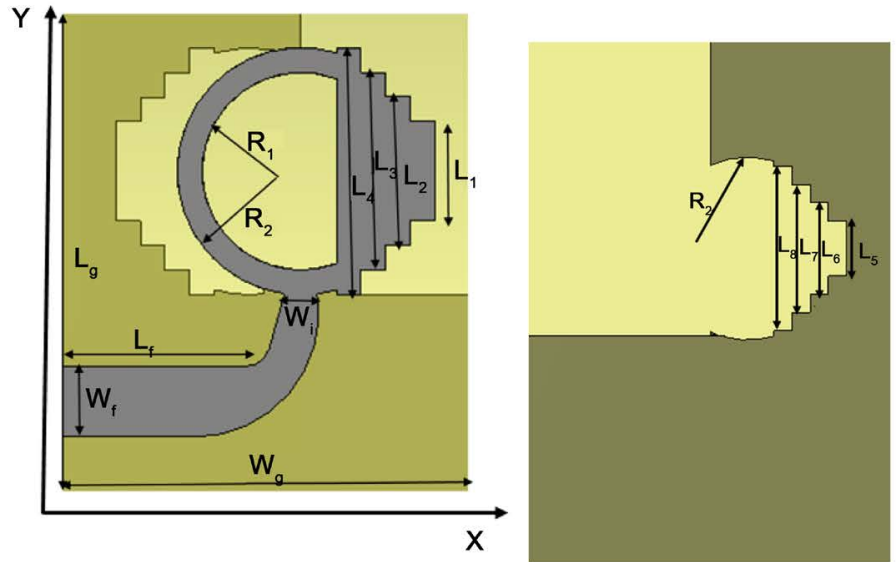

(e)

Figure 2. Design steps of the proposed antenna. (a) Antenna 1; (b) Antenna 2; (c) Antenna 3; (d) Antenna 4; (e) Antenna 5. 


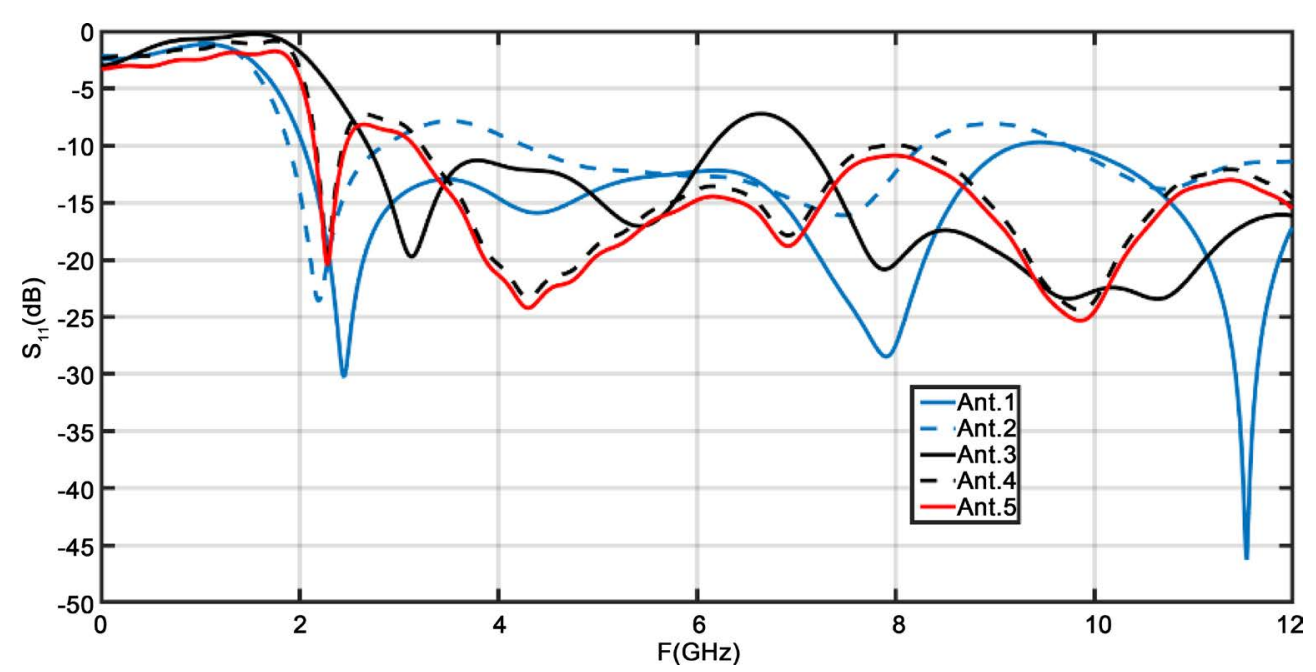

Figure 3. Return loss of the different antennas.

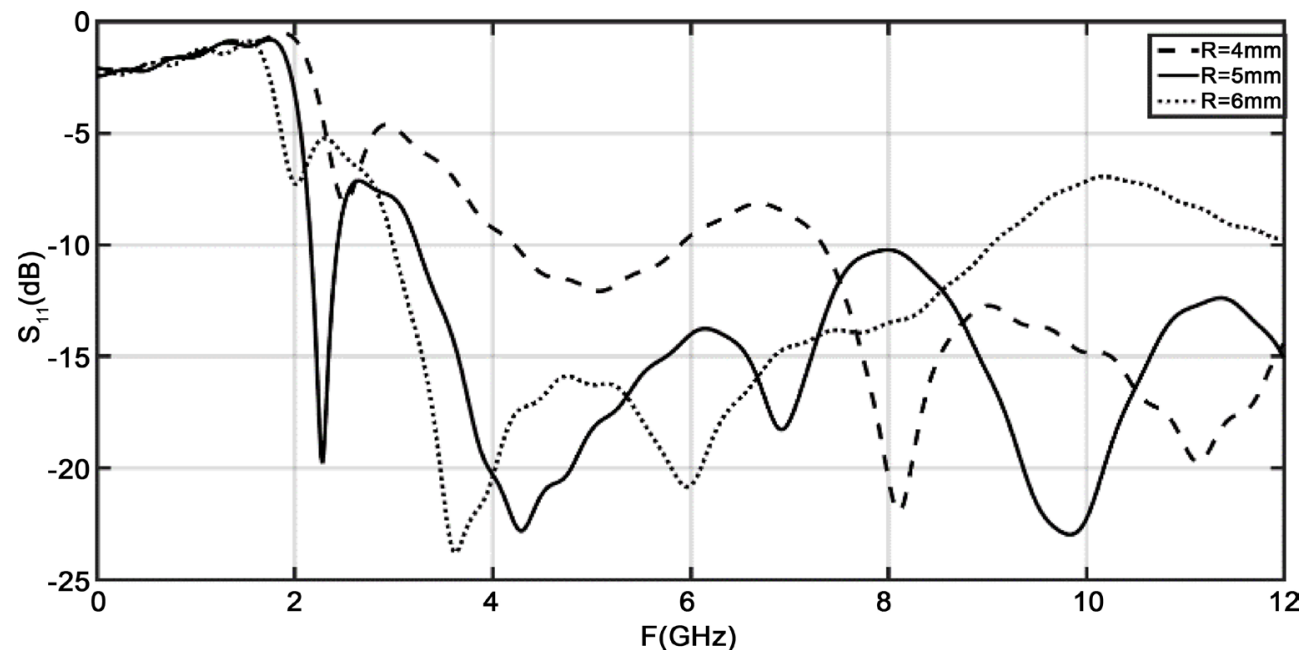

Figure 4. The return loss of the proposed antenna for different values of $R_{2}$.

Figure 4 illustrates the effect of varying outer radius $R_{2}$; it is noted that the optimum value is $\mathrm{R}_{2}=5 \mathrm{~mm}$. The impedance matching is controlling by $W_{i}$ as shown in Figure 5 to yield the best matching at $W_{i}=1.4 \mathrm{~mm}$. It is observed that as $W_{i}$ decreases more than $1.4 \mathrm{~mm}$ the matching is not good. Figure 6 shows the return loss of the antenna at different values of $\mathrm{L}_{1}=\mathrm{L}_{5}$, with $\mathrm{L}_{6}=\mathrm{L}_{2}=\mathrm{L}_{1}+2, \mathrm{~L}_{7}=$ $\mathrm{L}_{3}=\mathrm{L}_{1}+4, \mathrm{~L}_{8}=\mathrm{L}_{4}=\mathrm{L}_{1}+7$. The increasing of the length $\mathrm{L}_{1}$ will result in improves of the return loss and the bandwidth. Even though the $\mathrm{L}_{1}=5 \mathrm{~mm}$ provides the lowest return loss.

The antenna is fabricated on FR4 substrate and the prototype of the antenna is shown in Figure 7. The proposed antenna is simulated using the CST Microwave Studio 2016. Figure 8 shows the comparison between the simulated and the experimental results of the return loss. The simulated and the experimental results ensure that the antenna covers the UWB integrated with Bluetooth. It is clear that the simulated and measured have some little difference due to substrate loss, soldering and connectors which cannot be totally avoided. 


\section{Antenna Design with Notch}

In order to achieve the desired frequency band notch from $3.4-3.7 \mathrm{GHz}$ (WIMAX applications), a T-Shaped slit which equals half wavelength of the notched frequency is etched in radiating patch as illustrated in Figure 9.

Also, in order to reject frequency band of WLAN from $5.2-5.8 \mathrm{GHz}$, two

$\mathrm{C}$-shaped operate as parasitic elements with electrical length $0.5 \mathrm{dg}$ are placed on

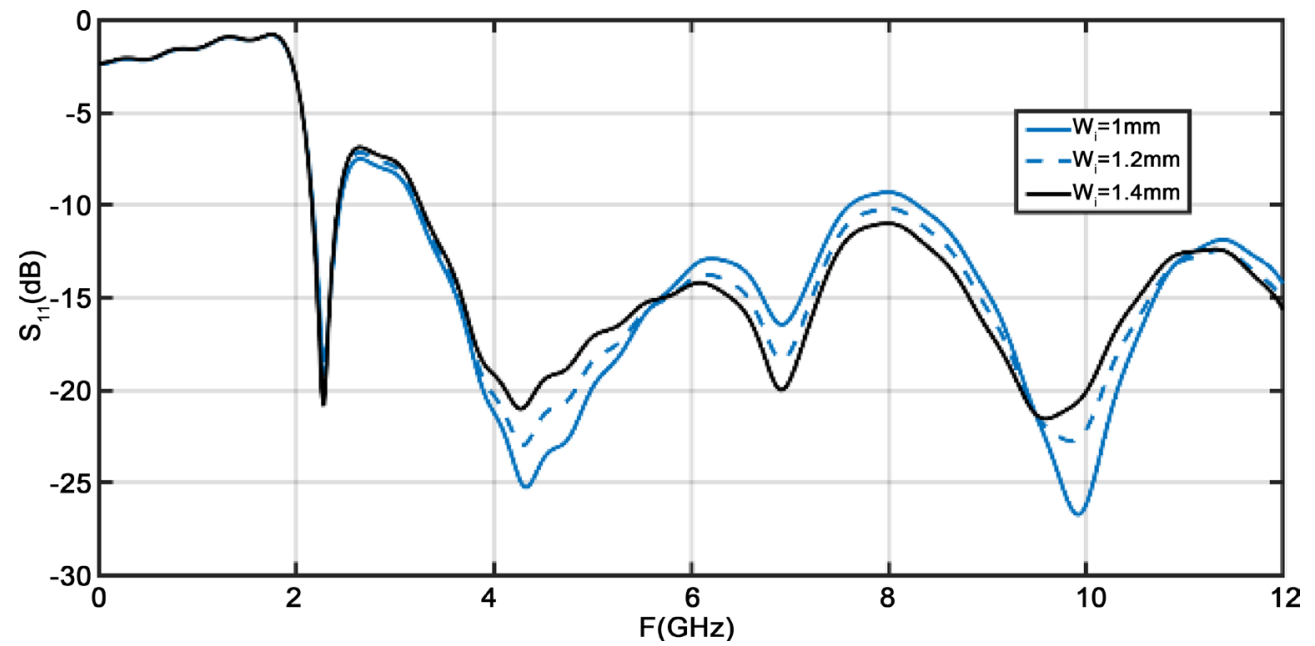

Figure 5. The return loss against frequency at different $W_{i}$

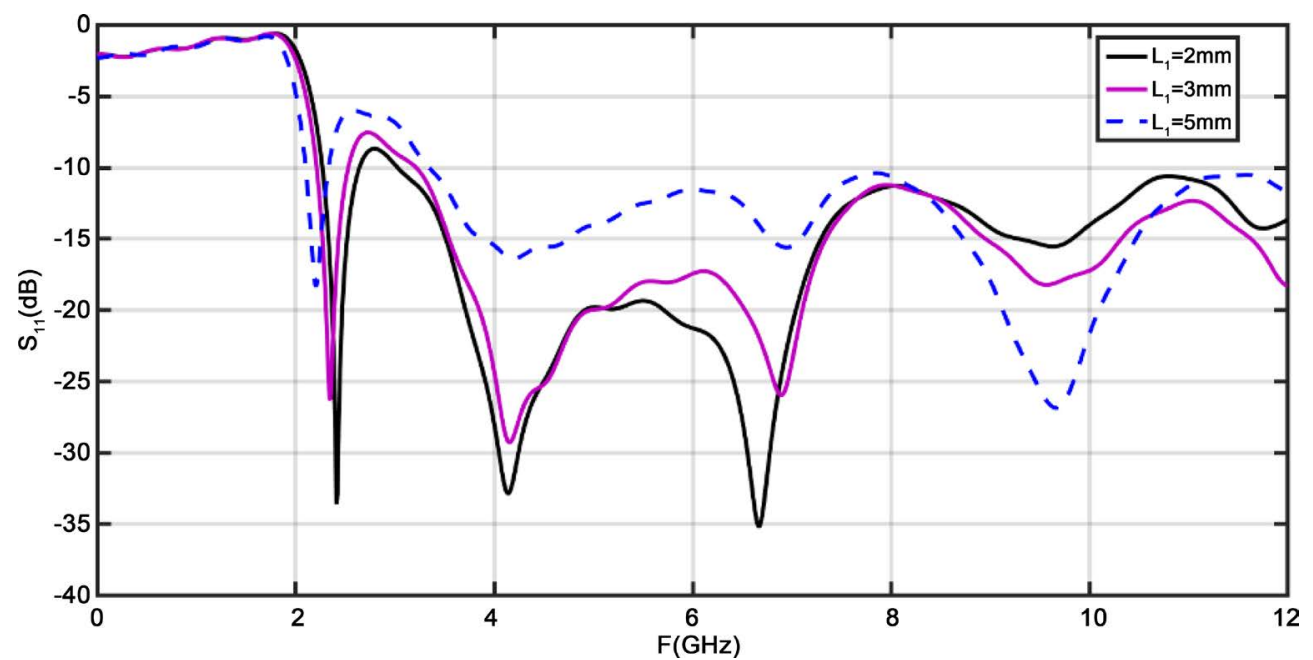

Figure 6. The return loss against frequency at different $L_{1}$.

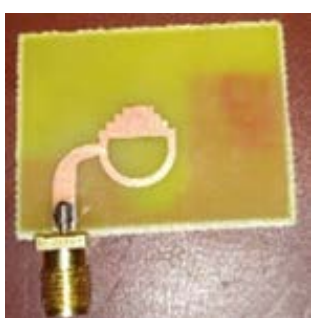

(a)

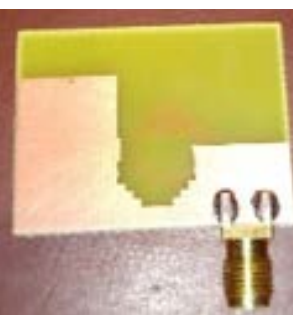

(b)

Figure 7. Prototype of the antenna. (a) Front View; (b) Back View. 


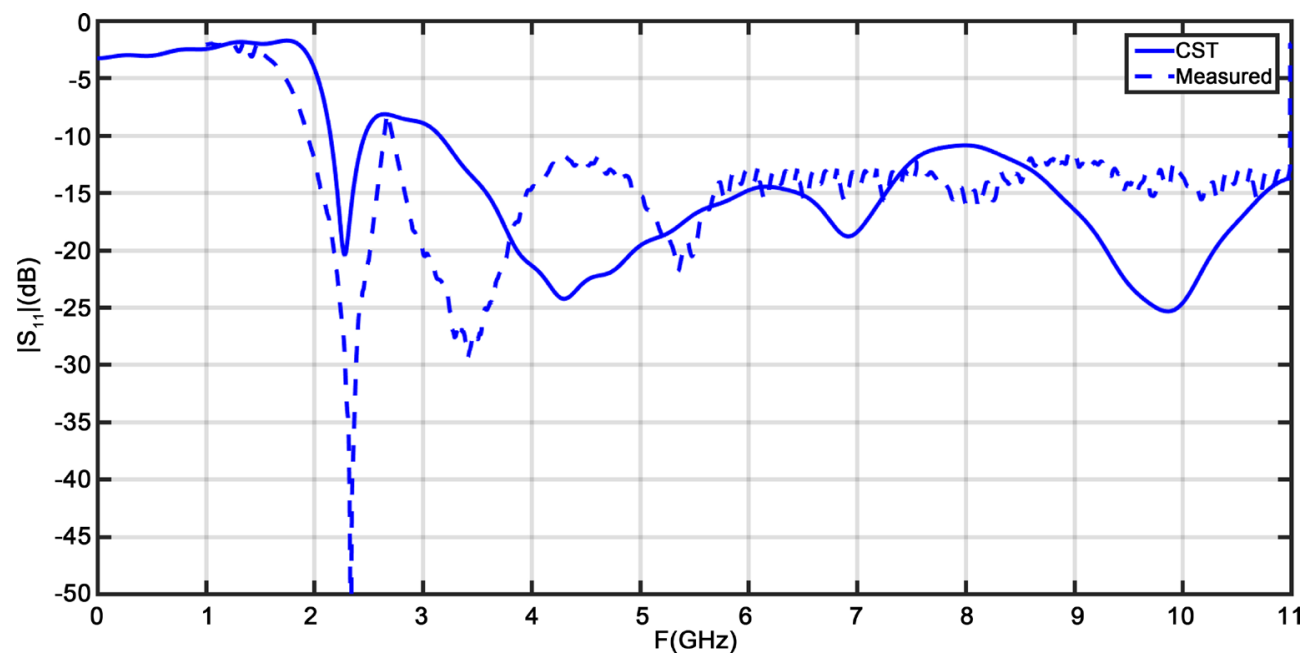

Figure 8. The return loss of the proposed antenna.

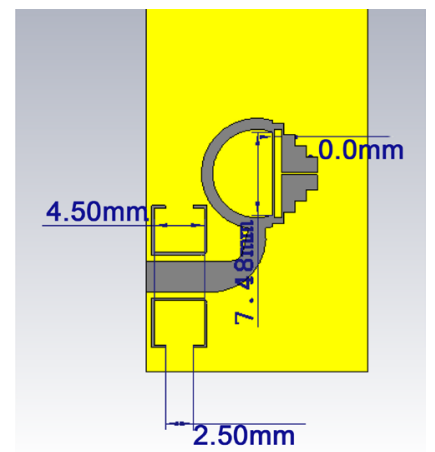

Figure 9. Antenna geometry with two notched.

top and below the horizontal feed line, as shown in Figure 9. The $\mathrm{T}$ and $\mathrm{C}$ Shapes are design using the following equations,

$$
f_{T-\text { notch }}=\frac{c}{4\left(L_{T}+W_{T}\right) \sqrt{\varepsilon_{e f f}}}, f_{C-\text { notch }}=\frac{C}{2 L_{C} \sqrt{\varepsilon_{e f f}}}
$$

The Prototype of the antenna is shown in Figure 10. Both Voltage Standing Wave Ratio (VSWR) for simulated and fabricated antenna are shown in Figure 11 . Very good agreement is observed.

Figure 12 and Figure 13 show a comparison between the simulated maximum gain and efficiency of the proposed antenna with and without notch, respectively. As shown in the figures, it is clear that in the case of without notch, the average gain equals approximately $3.5 \mathrm{~dB}$, and the averaged efficiency equals $75 \%$. On the other hand, the average peak gain and efficiency equal $3.5 \mathrm{~dB}$ and $70 \%$ except the two notched frequency bands. The peak gain and efficiency equal $-4 \mathrm{~dB},-1 \mathrm{~dB}$ and $23 \%, 43 \%$, respectively in the case of the presence of the notch. Figure 14 illustrates comparison between the simulated and measured radiation patterns in both the E- plane and H-plane at different frequencies. The radiation pattern of the proposed antenna is nearly figure of eight. Table 2 shows a comparison between the proposed antenna design and other published works. 


\section{Conclusion}

In this paper, a novel compact UWB antenna with notch for wireless applications is introduced. The proposed antenna is quasi-self-complementary feed by microstrip line and consists of semi-ring with tapered section for more matching. The prototype of the antenna is fabricated on FR-4 material. The dual
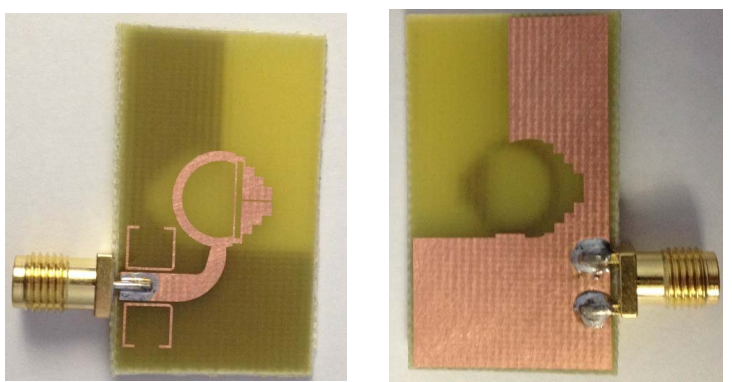

Figure 10. Fabrication antenna with two notches.

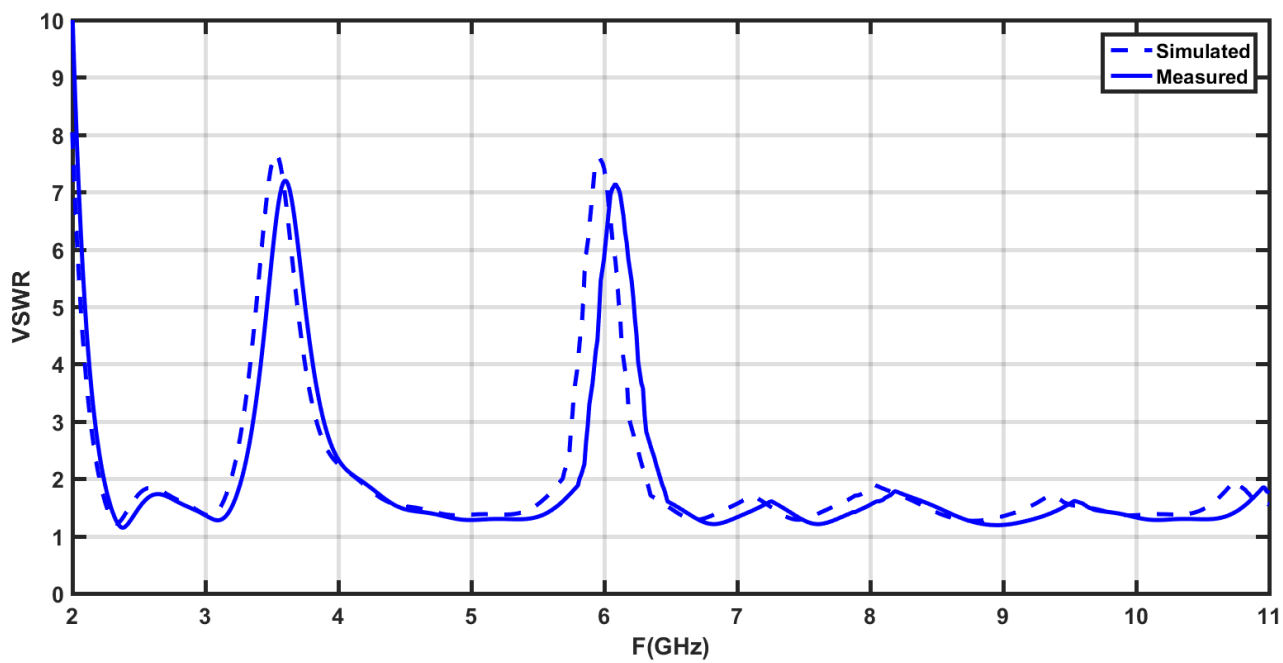

Figure 11. VSWR of the proposed antenna.

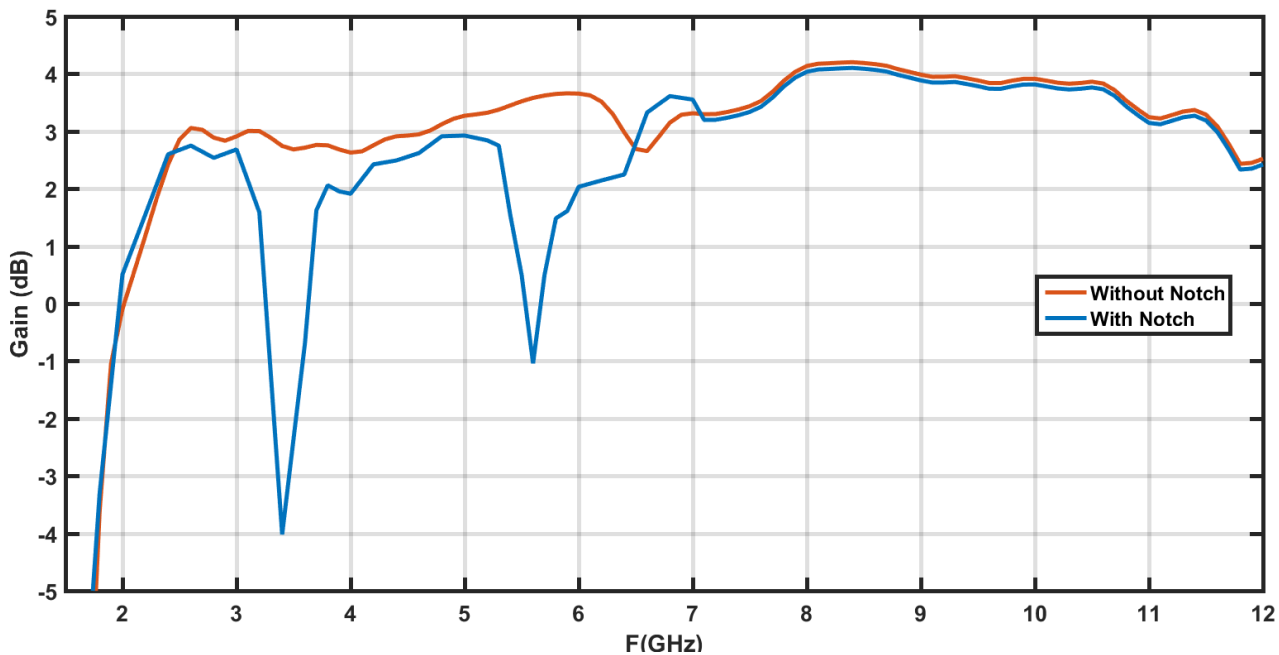

Figure 12. Simulated gain of the proposed antenna. 


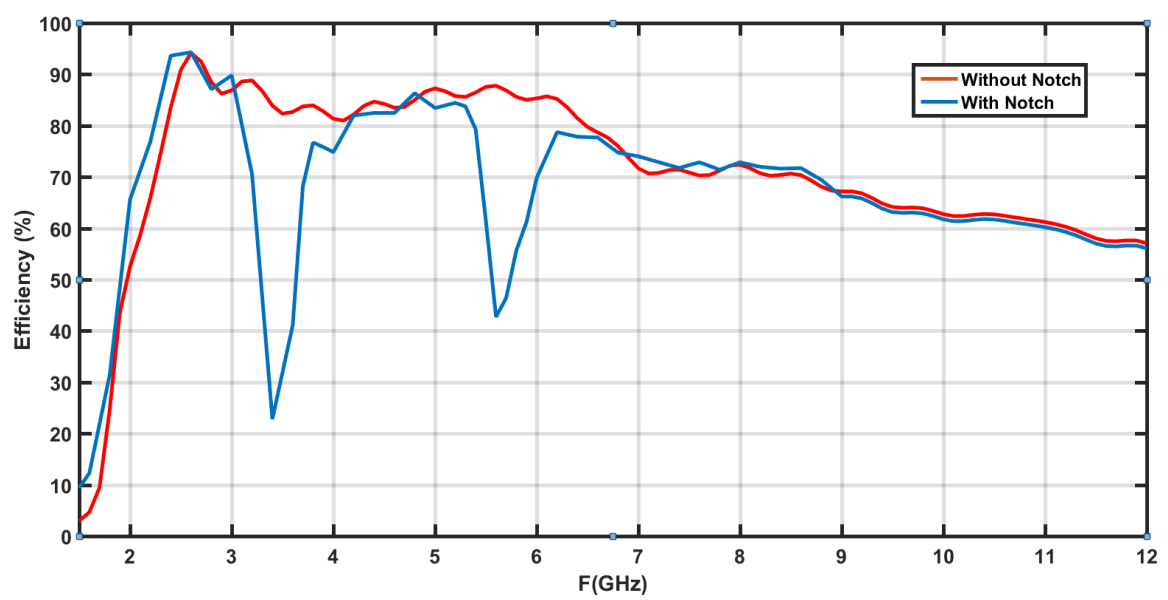

Figure 13. Simulated radiation efficiency of the proposed antenna.

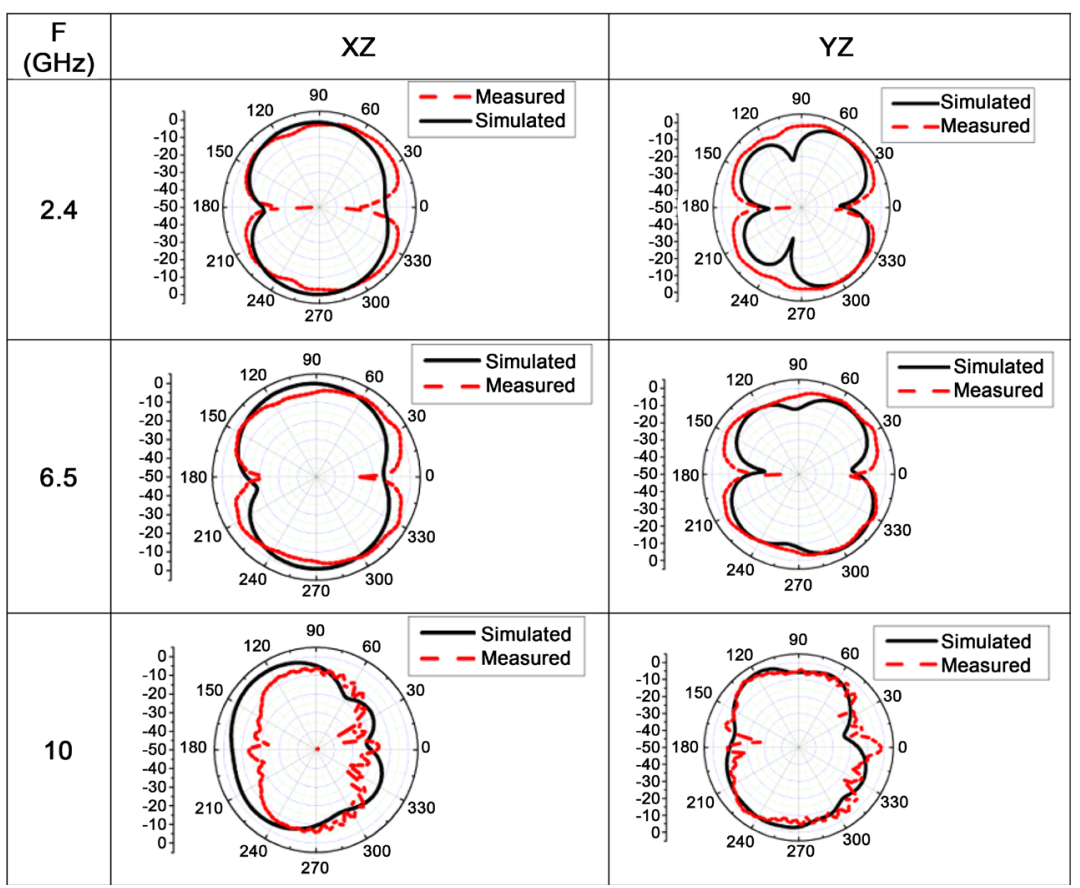

Figure 14. The radiation pattern of the proposed antenna at different frequencies.

Table 2. A comparison between the proposed antenna and other published papers.

\begin{tabular}{ccccc}
\hline Reference & Size $\left(\mathrm{mm}^{2}\right)$ & BW $(\mathrm{GHz})$ & Notch F $(\mathrm{GHz})$ & Realized Gain \\
\hline \multirow{2}{*}[5]{} & $30 \times 18$ & $2.28-12$ & 3.5 & 0.1 \\
& & & 5.5 & 0.2 \\
{$[11]$} & $16 \times 25$ & $2.8-14$ & 5.6 & -2.5 \\
& & & 3.5 & -4 \\
{$[17]$} & \multirow{2}{*}{$12 \times 18$} & $2.7-12$ & 5.5 & -4.5 \\
& & & 3.5 & -3.3 \\
{$[20]$} & \multirow{2}{*}{$12.3 \times 28$} & $3-12.8$ & 8.2 & -2.5 \\
& & & 3.6 & -4 \\
{$[21]$} & \multirow{2}{*}{$30 \times 30$} & $3.1-12$ & 5.5 & -2.5 \\
& & & 3.5 & -4 \\
This Work & \multirow{2}{*}{$11.5 \times 14.5$} & $2.2-14$ & 5.5 & -1 \\
\hline
\end{tabular}


notched bands are achieved by employing a $\mathrm{T}$-shaped slit etched in the radiating patch and two C-shaped are placed close to the microstrip feed line. The antenna has more compact size when compared to other published antennas. The antenna is simulated using the CST simulator and fabricated using the photolithographic technique. Very good agreement is obtained between the simulated and the experimental results.

\section{References}

[1] Lee, J.N., Kim, J.H., Park, J.K. and Kim, J.S. (2009) Design of Dual-Band Antenna with U-Shaped Open Stub for WLAN/UWB Application. Microwave and Optical Technology Letters, 51, 284-289. https://doi.org/10.1002/mop.24033

[2] Cheng, Y. and Hung, K. (2006) Compact Ultra-Wide Band Rectangular Aperture Antenna and Band-Notched Designs. IEEE Transactions on Antennas and Propagation, 54, 3075-3081. https://doi.org/10.1109/TAP.2006.883982

[3] Tang, M.C., Ziolkowski, R.W. and Xiao, S. (2014) Compact Hyper-Band Printed Slot Antenna with Stable Radiation Properties. IEEE Transactions on Antennas and Propagation, 62, 2962-2969.

[4] Sultan, K.S., Mohamed, H.A. and Eltayeb, M.M. (2015) Low SAR, Novel Compact Textile Wearable Antenna for Body Communications. 3rd International Conference on New Paradigms in Electronics \& Information Technology (PEIT015), Egypt, November, 1-4.

[5] Xiong, L. and Gao, P. (2012) Dual-Band Planar Monopole Antenna for Bluetooth and UWB Applications with WIMAX and WLAN Band-Notched. Progress in Electromagnetics Research Letters, 28, 183-194.

[6] Yildirim, B.S., Cetiner, B.A., Roqueta, G. and Jofre, L. (2009) Integrated Bluetooth and UWB Antenna. IEEE Antennas and Wireless Propagation Letters, 8, 149-152. https://doi.org/10.1109/LAWP.2009.2013371

[7] Li, Z.Q., Ruan, C.L. and Peng, L. (2010) Design and Analysis of Planar Antenna with Dual WLAN Band-Notched for Integrated Bluetooth and UWB Applications. Journal of Electromagnetic Waves and Applications, 24, 1817-1828.

[8] Sultan, K.S., Abdullah, H.H., Abdallah, E.A. and Hashish, E.A. (2013) Low SAR, Miniaturized Printed Antenna for Mobile, ISM, and WLAN Services. IEEE Antennas and Wireless Propagation Letters, 12, 1106-1109. https://doi.org/10.1109/LAWP.2013.2280955

[9] Li, D., Zhang, F.S., Zhao, Z.N., Ma, L.T. and Li, X.N. (2012) UWB Antenna Design Using Patch Antenna with Koch Fractal Boundary. IEEE Microwave and Millimeter Wave Technology Conference, 3, 1-3. https://doi.org/10.1109/ICMMT.2012.6230202

[10] Sultan, K.S., Abdullah, H.H. and Abdallah, E.A. (2016) Comprehensive Study of Printed Antenna with the Handset Modeling. Microwave and Optical Technology Letters, 58, 974-980. https://doi.org/10.1002/mop.29711

[11] Abd El-Hameed, A.S., Salem, D.A., Abdallah, E.A. and Hashish, E.A. (2013) Quasi Self Complementary UWB Notched Microstrip Antenna for USB Application. Progress in Electromagnetics Research B, 56, 185-201.

[12] Wahab, M.G., Abd El-Hameed, A.S., Swelam, W. and Abd ElAzeem, M.H. (2016) Design of Miniaturized Fractal Quasi-Self Complimentary Antenna for UWB Applications. Antenna and Propagation Symposium, Fajardo, 26 June-1 July 2016, 1809-1810. 
[13] Patil, S., Gupta, R. and Kharche, S. (2017) Gain Improvement of Lower UWB Monopole Antenna using FSS Layer. International Conference on Nascent Technologies in Engineering, 1-5. https://doi.org/10.1109/ICNTE.2017.7947955

[14] Kang, X., Zhang, H., Li, Z., et al. (2013) A Band-Notched UWB Printed Half Elliptical Ring Monopole Antenna. Progress in Electromagnetics Research C, 35, 23-33. https://doi.org/10.2528/PIERC12082818

[15] Karmakar, A., Ghatak, R., Banerjee, U. and Poddar, D.R. (2013) An UWB Antenna using Modified Hilbert Curve Slot for Dual Band Notch Characteristics. Journal of Electromagnetic Waves and Applications, 27, 1620-1631.

https://doi.org/10.1080/09205071.2013.821676

[16] Bing, L. and Hong, J.S. (2012) Design of Two Novel Dual Band Notched UWB Antennas. International Journal of Antennas and Propagation, 2012, Article ID: 303264.

[17] Ojaroudi, N. and Ojaroudi, M. (2013) Novel Design of Dual Band Notched Monopole Antenna with Bandwidth Enhancement for UWB Applications. IEEE Antennas and Wireless Propagation Letters, 12, 698-701. https://doi.org/10.1109/LAWP.2013.2264713

[18] Soltani, S., Azarmanesh, M., Lotfi, P. and Dadashzadeh, G. (2011) Two Novel Very Small Monopole Antennas Having Frequency Band Notch Function using DGS for UWB Application. International Journal of Electronics and Communications, 65, 87-94.

[19] Li, T., Zhai, H.Q., Zhu, C., Li, L., Liang, C.H. and Han, Y.F. (2013) Design and Analysis of Compact Printed Dual Band-Notched Ultra Wideband (UWB) Antenna. Journal of Electromagnetic Waves and Applications, 27, 560-571. https://doi.org/10.1080/09205071.2013.756796

[20] Li, E., Li, Y.W. and Ye, Q. (2013) Miniaturization of Asymmetric Coplanar Strip-Fed Staircase Ultra Wide Band Antenna with Reconfigurable Notch Band. Microwave and Optical Technology Letters, 55, 1467-1470. https://doi.org/10.1002/mop.27634

[21] Ibrahim, A.A., Abdalla, M.A. and Boutejdar, A. (2017) A Printed Compact Band-Notched Antenna using Octagonal Radiating Patch and Meander Slot Technique for UWB Applications. Progress in Electromagnetics Research M, 54, 153-162. https://doi.org/10.2528/PIERM16122805

\section{Submit or recommend next manuscript to SCIRP and we will provide best service for you:}

Accepting pre-submission inquiries through Email, Facebook, LinkedIn, Twitter, etc. A wide selection of journals (inclusive of 9 subjects, more than 200 journals) Providing 24-hour high-quality service User-friendly online submission system Fair and swift peer-review system Efficient typesetting and proofreading procedure Display of the result of downloads and visits, as well as the number of cited articles Maximum dissemination of your research work

Submit your manuscript at: http://papersubmission.scirp.org/ Or contact ojapr@scirp.org 